\title{
Gastrointestinal stromal tumor: pathological and clinical characteristics in the population of the General Hospital of Mexico "Dr. Eduardo Liceaga"
}

\author{
Avissai Alcántara-Vázquez ${ }^{1,2 *}$, Óscar Chapa-Azuela ${ }^{3}$, Luis Díaz-Rodríguez ${ }^{4}$ and \\ Mercedes Hernández-González ${ }^{1,2}$ \\ ${ }^{1}$ Unidad de Patología, Hospital General de México "Dr. Eduardo Liceaga", Mexico City, Mexico; ' 2 Departamento de Patología, Facultad de Medicina, \\ UNAM, Mexico City, Mexico; ${ }^{3}$ Servicio de Cirugía General, Hospital General de México "Dr. Eduardo Liceaga", Mexico City, Mexico; ${ }^{4}$ Servicio de \\ Oncología, Hospital General de Mexico "Dr. Eduardo Liceaga”, Mexico City, Mexico
}

\begin{abstract}
The gastrointestinal stromal tumors (GISTS) are neoplasms of mesenchymal origin; they represent $0.3 \%$ of neoplasm in the digestive tube. They are defined by the expression of CD117, a tyrosine kinase receptor of the growth factor. Our objective is to know the clinical, pathological, and immunohistochemical characteristics in the population who attend the general hospital of Mexico. The cases of mesenchymal tumors in the digestive system during the period of July 2010-May 2017 were revised. Fifty-four cases of GIST were found; in all cases, clinical data and the macroscopic aspect were studied, and microscopy and immunohistochemical characteristics were also checked. These cases are more frequent in women, in a proportion of 1.2:1, with an average age of 54-year-old. The treatment was full surgery, in 4 of them, a lymphadenectomy was done, and metastasis was found in one case. The average size of the tumors was $8 \mathrm{~cm}$. The predominant histological pattern was fusocellular (81.5\%), followed by epithelioid patterns (7.4\%) and mixed (11.1\%). The main locations were the stomach $(48.1 \%)$, small intestine (40.7\%), rectum (5.6\%), omentum (3.7\%), and mesentery (1.9\%). The malignant potential according to Fletcher's criteria were very low malignant potential (20.5\%), low malignant potential (25\%), intermediate potential (20.5\%), and high malignant potential (34.1\%). All cases were positive for CD117.
\end{abstract}

Key words: Gastrointestinal stromal tumor. C-KIT. CD117.

\section{Introduction}

These are neoplasms made up of spindle cells and/or epithelioid and occasionally pleomorphic cells, which originate from interstitial cells of Cajal (ICC), with mutations in the receptor tyrosine kinase genes, which distinguish them from other tumors.

In the decades from 30 to 50 of the $20^{\text {th }}$ century, these tumors were classified as leiomyomas or leiomyosarcomas and tumors with epithelioid features were designated as leiomyoblastomas or epithelioid leiomyosarcomas.

Dudley cols in 1942 and Rabinovich et al. in 1949 considered that these neoplasms had a benign evolution. In counterpart France and Brenes in 1950, as well as Martin in 1960, they saw that some of these tumors were malignant and also suggest their myoid nature ${ }^{1}$.

In the decade from 60 to 70 , electron microscopy (EM) showed the absence of muscle differentiation.

\section{Correspondence:}

Avissai Alcántara-Vázquez

E-mail: avissai@ hotmail.com
Date of reception: 30-03-2017

Date of acceptance: 03-02-2018

DOI: 10.24875/HGMX.M19000002
Available online: 21-03-2019

Rev Med Hosp Gen Mex. 2019;82(1):4-10 www.hospitalgeneral.mx under the CC BY-NC-ND license (http://creativecommons.org/licenses/by-nc-nd/4.0/). 
The term gastrointestinal stromal tumor (GIST) was introduced by Mazur and Clark $^{2}$ in 1983, working with immunohistochemistry $(\mathrm{IHC})$ and $\mathrm{ME}$ techniques, determining that they did not have smooth muscle cell characteristics, whereas GIST was occasionally protein positive. S-100 proposes a Schwannian origin from the myenteric plexus.

In 1984, Herrera et al. ${ }^{3}$ confirmed the neural nature of an intestinal malignancy by calling it plexosarcoma and because it coincided with a publication of a similar tumor with neuroendocrine differentiation by Walker and Dvorak these tumors were classified within the GIST, but considering a possible neuroendocrine differentiation'.

In 1987, Barker and Rudolfe ${ }^{4}$ succeeded in cloning the c-kit, using somatic human-mouse hybrid cells, locating the gene on chromosome 4. 2 years later, d'Auriol et al. ${ }^{5}$ located the gene in the 4 q11-q12 region.

In 1990, the mesenchymal nature of the tumor was confirmed by $\mathrm{IHC}$, given that between $60 \%$ and $70 \%$ were positive for CD34 (hematopoiesis progenitor cell antigen), and this is being the first relatively specific marker of the GIST.

Kindblom et al. ${ }^{6}$ argued that the GIST was related to the ICC, the myenteric plexus, and they form a network located in the plexus of Auerbach, regulating the communication between neurons and muscle fibers, and act as a pacemaker controlling peristalsis, muscle contraction, and possibly as mediators of neurotransmitters ${ }^{7}$.

Histogenetically, ICC has a mesenchymal origin, and they differ from an intestinal precursor cell which also gives rise to smooth muscle cells. The expression of $c$-kit proto-oncogene and the precursor cell factor receptor would be necessary for the proliferation and differentiation of the precursor cells toward $\mathrm{ICC}^{8}$.

The absence of neuroendocrine differentiation of ICC, evidenced by EM, excludes that these cells have a bifunctional, neural, and muscular capacity ${ }^{9}$.

Kitamura et $a .^{10}$ discovered the increased function by mutation of the c-kit proto-oncogene and overexpression of CD117. Later, Lasota et al. ${ }^{11}$ demonstrated that c-kit mutations and positivity for c-kit occurred only in GIST. In addition, the interaction between c-kit and its ligand factor precursor cells (stem cell factor) that binds to the intracellular receptor is vital for cell survival, proliferation, and differentiation.

Heinrich et al. ${ }^{12}$ reported that the possibility of a second receptor involved in the pathogenesis of GIST was raised, especially in those lacking mutations in c-kit, and found a second in the platelet-dependent epidermal growth factor alpha (PDGFR $\alpha$ ) receptor.
In 2001, Joensuu et al..$^{13}$ described the first case of GIST, treated with imatinib, designed for the treatment of chronic myeloid leukemia, but which can act on proteins with tyrosine kinase activity, such as c-kit receptors and PDGFR $\alpha$ receptors.

The aim of this study was to describe the clinical pathological aspects and IHC of the neoplasms diagnosed as GIST, in the Surgical Pathology Unit from Hospital General de México "Dr. Eduardo Liceaga", during the period from July 2010 to May 2017, as well as review the literature relevant to this process.

\section{Materials and methods}

We reviewed the cases of mesenchymal tumors of the digestive system, during the period from July 2010 to May 2017, which had lamellae and paraffin blocks, to make additional histological sections if necessary; likewise, they had studies of IHC, for CD117, anti-smooth muscle actin (AAML), and S-100 protein (PS-100).

From the microscopic study and IHC of the mesenchymal tumors, 54 were found which fulfilled the GIST criteria. The microscopic study also allowed obtaining data regarding histological pattern, number of mitosis, histological type, state of the borders, necrosis, and differentiation. From the anatomopathological report, data were obtained on the clinical diagnosis, age and sex of the patient, and size and location of the tumor, and with all this information, an overview of the risk factors was formed, which determine the malignant behavior of these neoplasms.

\section{Results}

In 54 cases of GIST, the clinical diagnosis was of tumor in 28 cases (51.9\%), of probable GIST in 21 (38.9\%), gastric $\mathrm{Ca}$ in 3 cases $(5.6 \%)$, perforation of 1 case $(1.9 \%)$, and acute abdomen in 1 case (1.9\%). The average age of the group was 54 years, with limits between 22 years the least and 81 years the highest. Regarding sex, 29 cases (53.7\%) were women and 25 (46.7\%) were men. The ratio of women to men is 1.2:1.

Regarding localization, 26 cases $(48.1 \%)$ were in the stomach, $5(9.3 \%)$ in the duodenum, $8(14.8 \%)$ in the jejunum, 9 cases $(16.7 \%)$ in the ileum, $3(5.6 \%)$ in the rectum, $2(3.7 \%)$ in omentum, and $1(1.9)$ in the mesentery. When correlating the location with the age group, it was found that, in 24 cases (44.4\%), it was between 21 and 50 -year-old, 25 cases (46.3.3\%) between 51 and 75 -year-old, and $5(9.3 \% \%)>75$-year-old 
Table 1. Age and location

\begin{tabular}{|l|c|c|c|c|c|c|c|}
\hline \multirow{2}{*}{ Age groups } & \multicolumn{7}{|c|}{ Locations } \\
\cline { 2 - 9 } & Stomach & Duodenum & Jejunum & llium & Rectum & Epiplon & Mesentery \\
\hline$<20$ years & & & & & 1 & \\
\hline $21-50$ years & 10 & 4 & 4 & 5 & 1 & 2 & 1 \\
\hline $51-75$ years & 13 & 1 & 4 & 3 & 1 & 2 & 1 \\
\hline$>75$ years & 3 & & & 1 & 3 & 2 & 1 \\
\hline Total & 26 & 5 & 8 & 9 & & 2 & \\
\hline
\end{tabular}

Table 2. Size and staging of neoplasias in $44^{*}$

\begin{tabular}{|c|c|c|c|c|}
\hline \multicolumn{5}{|c|}{ Cases } \\
\hline Location & $<2 \mathrm{~cm}$ & $2 \mathrm{~cm}<5 \mathrm{~cm}$ & $>5 \mathrm{~cm}<10 \mathrm{~cm}$ & $>10 \mathrm{~cm}$ \\
\hline & T1 & T2 & T3 & T4 \\
\hline Stomach & & 5 & 7 & 7 \\
\hline Duodenun & & 5 & & \\
\hline Yeyunum & 1 & & 1 & 1 \\
\hline Ilium & 1 & 2 & 3 & 4 \\
\hline Rectum & 1 & & 1 & \\
\hline Epiplón & & 2 & 2 & \\
\hline Mesentery & & & & 1 \\
\hline Total & $3(6.8 \%)$ & $14(31.8 \%)$ & $14(31.8 \%)$ & $13(29.6 \%$ \\
\hline
\end{tabular}

*Ten cases were biopsies or cases of revision of lamellae, therefore there is no data on the size of the tumor.

Table 3. Index of mythosis for 50 fields of great increase

\begin{tabular}{|c|c|c|c|c|}
\hline Location & $<2$ to 2 & 2 to $<5$ & $>5$ to $<10$ & $>10$ \\
\hline Stomach & 18 & 3 & 2 & 3 \\
\hline Duodenun & 5 & & & \\
\hline Yeyunum & 5 & 1 & 1 & 1 \\
\hline Ilium & 3 & 3 & 2 & 1 \\
\hline Rectum & 1 & 1 & 1 & \\
\hline Epiplón & & 1 & & 1 \\
\hline Mesentery & & & & 1 \\
\hline Total & $32(59.3 \%)$ & $9(16.7 \%)$ & $6(11.1 \%)$ & $7(12.9 \%)$ \\
\hline
\end{tabular}

(Table 1). The size of the tumors could only be obtained in 44 of the 54 cases and ranged from $1 \mathrm{~cm}$ the least to $30 \mathrm{~cm}$ the greatest, with an average of $8 \mathrm{~cm}$. (Fig. 1); nevertheless, tumors of $1 \mathrm{~cm}$ only there were $1(2.3 \%)$ and tumors $>10 \mathrm{~cm} .13$ (29.6\%) (Table 2).
Regarding the mitosis index for 50 high-gain fields (CGA, by its abbreviation in Spanish), we found $<2.32$ cases $(59.3 \%) ;>2<5$ mitosis for 50 CGA, $9(16.7 \%) ;>5<10$ mitosis for 50 CGA, $6(11.1 \%)$; and $>10$ mitosis for 50 CGA, 7 (12.9\%) (Table 3). 


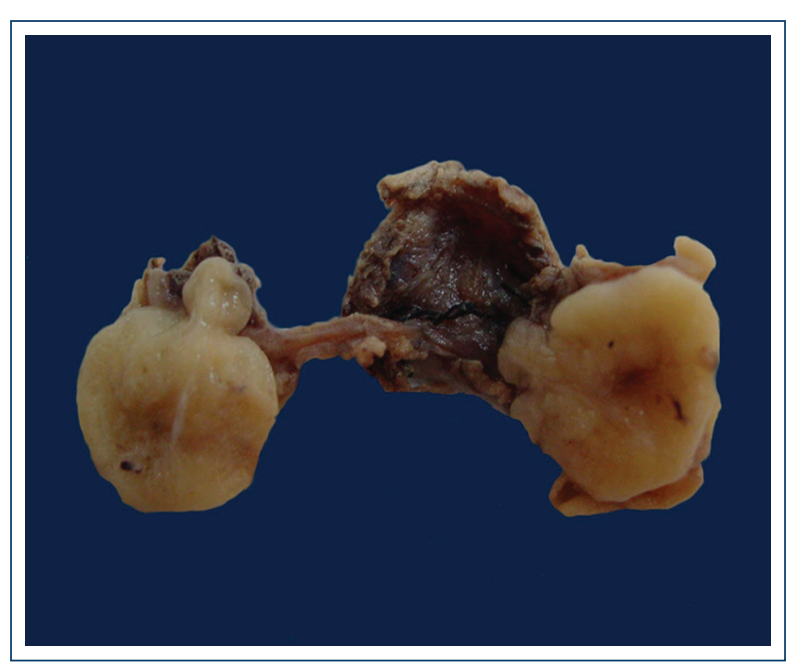

Figure 1. Macrophotography of duodenal gastrointestinal stromal tumor, well limited, rounded, grayish brown and fasciculate appearance.

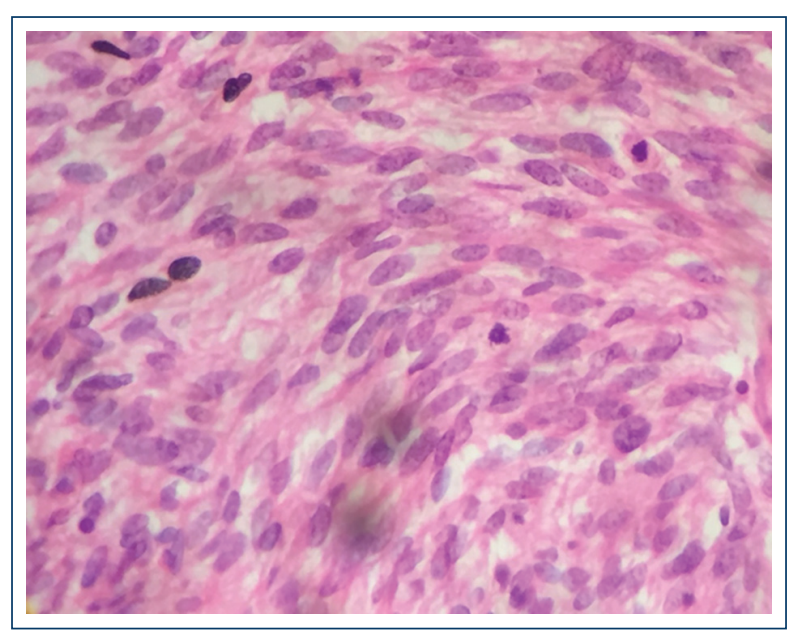

Figure 2. Microscopic image of gastrointestinal stromal tumor with a fusocellular pattern and a mitosis figure in the central part of the $\mathrm{HE} \times 200$ image.

Regarding the histological type, the fusiform variety (Fig. 2) was present in 44 cases (81.5\%), the epithelioid form (Fig. 3 ) in 4 cases (7.4\%), and mixed type (Fig. 4) in 6 cases (11.1\%). Regarding the borders, 41 cases $(78.8 \%)$ had rounded edges and 11 (21.2\%) had infiltrating edges. In the cases with infiltrating edges, 6 tumors were gastric, 2 of jejunum, 2 of ileum, and 1 of mesentery. Two more cases corresponded to biopsies, and it was not possible to determine the characteristics of the infiltration.

In the IHC study of the 54 cases, all were positive for CD117 (Fig. 5) and the reactions for AAML and PS-100 were negative. In four cases, lymphadenectomy was

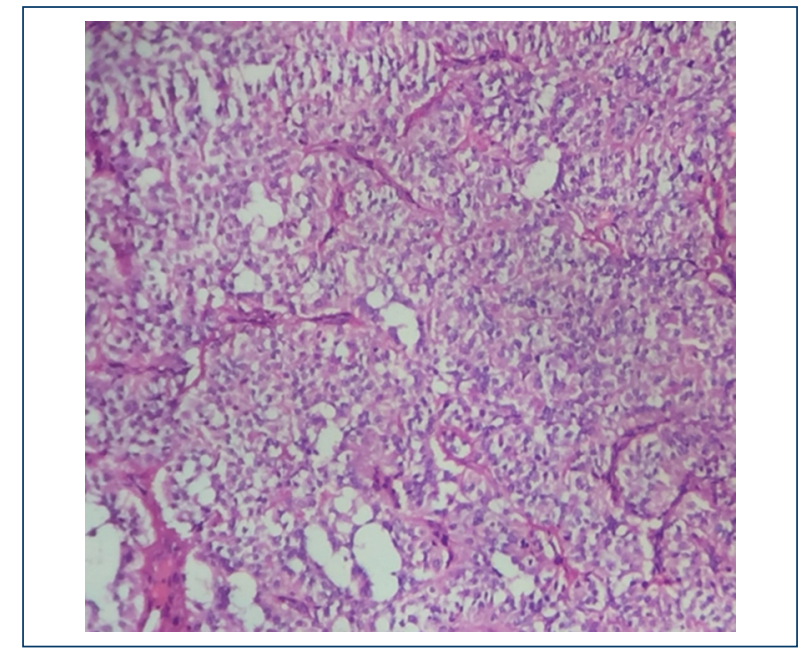

Figure 3. Gastrointestinal stromal tumor of epithelioid type with a pseudoalveolar histological pattern $\mathrm{HE} \times 200$.

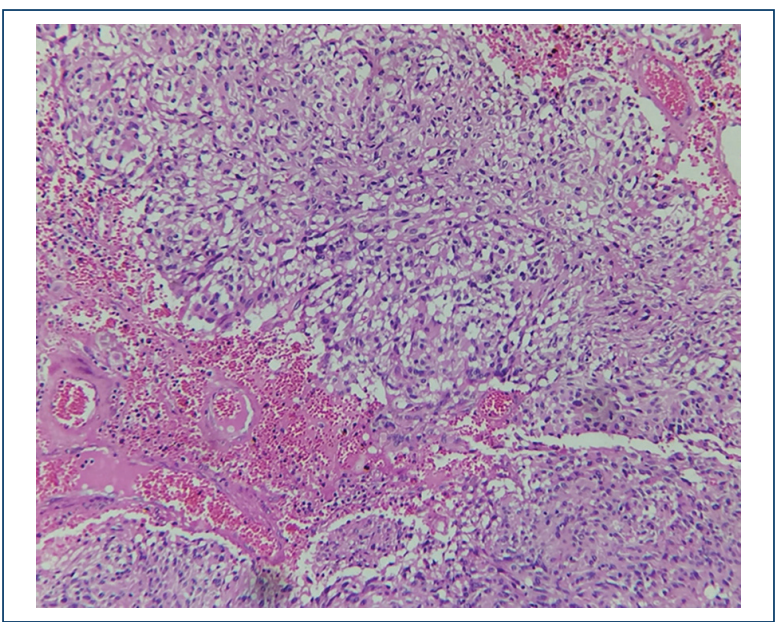

Figure 4. Microphotography showing a mixed image of gastrointestinal stromal tumor, a fusocellular pattern and an epithelioid $\mathrm{HE} \times 400$.

performed, and in one case of high-grade jejunum GIST, there was metastasis to a regional lymph node (Fig. 6).

\section{Discussion}

GIST is neoplasms of mesenchymal origin, constituting a group of lesions characterized immunohistochemically by expressing in $>90 \%$ of cases the transmembrane receptor derived from the stem cell, with activity on the receptor tyrosine kinase known as CD117 or c-kit.

The incidence of GIST is $10-20$ cases per $10,00,000$ inhabitants. It occurs around 50 years with an average 


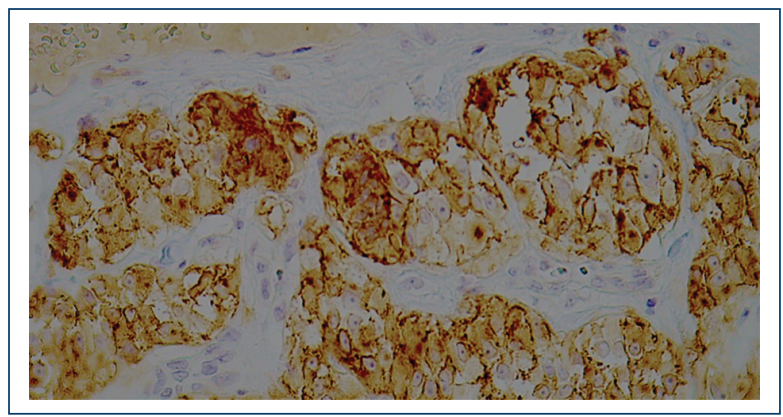

Figure 5. Positive immunohistochemistry for CD117 in an epithelioid-type gastrointestinal stromal tumor.

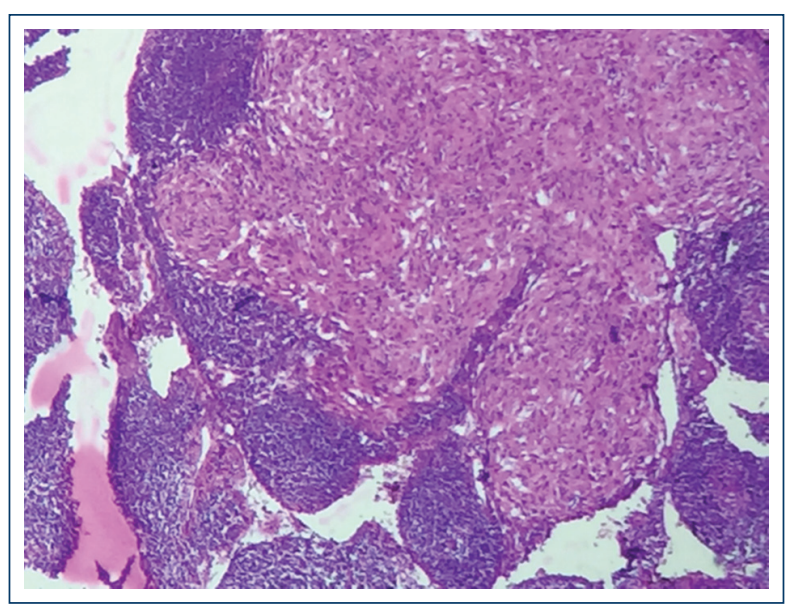

Figure 6. Ganglionar metastasis.

of 55-65 years. In our cases, the youngest was 22-yearold and the oldest 81-year-old, with an average of 54 years, which agrees with that reported in the literature. It is most commonly located in the stomach (50\%-60\%), followed by the small intestine $(20 \%)$, colon and rectum $(10 \%)$, and esophagus $(<5 \%)$. Occasionally, they are located in omentum, mesentery, retroperitoneum, pancreas, and gallbladder ${ }^{14}$. In our tumors, it was in descending order: the stomach $(48.1 \%)$, small intestine $(40.8 \%)$, rectum $(5.6 \%)$, omentum $(3.7 \%)$, and mesentery $(1.9 \%)$.

The symptoms depend on the size of the GIST; thus, gastric tumors present with abdominal pain or hemorrhage. In GIST of the small intestine are pain, hemorrhage or signs of obstruction ${ }^{15}$. In the Mexican population, Medina et al. ${ }^{16}$ found that the main symptoms are abdominal pain $(56 \%)$, digestive tract hemorrhage $(38.7 \%)$ anemia $(34.1 \%)$, vomiting (16.1\%), abdominal distension (12.9\%), weight loss (12.9\%), and postprandial fullness $(6.5 \%)$.
The reported size of the tumors is between $0.3 \mathrm{~cm}$ the smallest and $38 \mathrm{~cm}$ the oldest. We found that the largest tumor was $30 \mathrm{~cm}$ and the smaller than $1 \mathrm{~cm}$ with an average of $8 \mathrm{~cm}$. As for gender, they occur more frequently in men; however, in our casuistry, the woman was mostly affected in a 1.2:1 ratio.

Within the organ affected by the tumor, it may have an intramural, submucosal, or suberosa location. When cut the surface is of variable color depending on the degree of hemorrhage, its color may be grayish, whitish, reddish, or brownish. They are usually fleshy looking solids, with cystic or necrotic areas ${ }^{17}$. Of our cases, $13 \mathrm{had}$ necrosis, 10 of which measured $>10 \mathrm{~cm}$ and 3 $<10 \mathrm{~cm}$.

Histologically, GIST presents different cell morphologies: spindle cells $(77 \%)$, epithelioid cells $(8 \%)$, and the mixed form $(15 \%)^{14}$. The proportion found in our casuistry was spindle cells $(81.5 \%)$, cell epithelioid $(7.4 \%)$, and mixed variety (11.1\%).

Fusocellular tumors are composed of cells with a fusiform nucleus, scarce eosinophilic or pale cytoplasm, and a fibrillar aspect. They grow without a defined pattern, fusocellular, verticillate, storiform, or palisading, like peripheral nerve tumors. In the cases of this report, we found two with neurofibroma-like pattern, one with a storiform pattern, and the other with cellular pleomorphism.

Epithelioid tumors have extensive, eosinophilic, oncocytic, or clear cytoplasm; they can present perinuclear glycogen, and the histological pattern can be organoid, trabecular, alveolar, or insular. Mixed tumors show transition between the epithelioid and spindle cell fields.

Between $80 \%$ and $100 \%$ of GISTs show mutations in one or both tyrosine kinase receptors, which are the kit gene and PDGFR $\alpha$. Tyrosine kinase is detectable by IHC with CD117 antigen, which produces a strong and diffuse staining cytoplasmic. Our cases were all positive $(54 / 54)$ to CD117.

A small proportion of GIST is negative for CD117; in this situation, a marker that is independent of the kit or PDGFRa mutations has been described, and it is a protein of the calcium and chlorine regulatory channel called DOG 1 (Anoctamin 1). It is an antibody with greater sensitivity to CD117 but with relative specificity, since it has been positive in several carcinomas and some sarcomas ${ }^{18,19}$. Negative cases of DOG and kit can be diagnosed with the protein kinase theta, which is expressed in all GISTs regardless of their mutational status $^{20}$.

The mutation of the kit gene is an early event in GIST, with the mutation of exon 11 being the most common. 
Secondary mutations are also found in exons 13, 14, 17 , or 18. Studies of mutations are necessary when GISTs do not react to CD117 19,21 .

Approximately $10 \%$ of GISTs do not detect mutations in c-kit or PDGFRa and it is called wild-type (WT); in spite of not detecting these mutations, the tyrosine kinase is activated. In the GIST of the WT variety, several oncogenic mutations have been described, such as BRAF, which encodes a serine/threonine protein kinase, which plays an important role in the regulation of the cell cycle and oncogenic modification of cellular responses to growth signals via Mitogen-activated protein kinase 22 .

Between 2005 and 2006, Miettinen and Lasota ${ }^{23}$ added the location parameter to the Fletcher ${ }^{24}$ classification, finding that the intestinal GIST of the jejunum and ileum with a similar size and mitosis activity to the gastric ones are more aggressive. In our cases, there are few examples and we do not have data on the evolution after surgery, of the GIST reported here, to reach these conclusions (Tables 2 and 3). However, in Mexico, Medrano et al. ${ }^{25}$ found, in a study of 66 cases of GIST, that the variable that showed statistical significance in survival was localization, and in intestinal lesions, the survival was lower.

In 2010, the International Union Against Cancer $(\mathrm{UICC})^{26}$ presented a new classification TNM: T1 tumor $<2 \mathrm{~cm}$, T2 tumor $>2 \mathrm{~cm}>5 \mathrm{~cm}$, T3 tumor $>5 \mathrm{~cm}<10 \mathrm{~cm}$, and $\mathrm{T} 4$ tumor $>10 \mathrm{~cm}$. According to this classification, our cases behaved as follows: T1, 3 cases $(6.8 \%)$; T2, 14 cases $(31.8 \%)$; T3, 14 cases $(31.8 \%)$; and T4, 13 cases $(29.6 \%)$ (Table 2).

The same UICC ensures the histological grade according to the number of mitoses by 50 CGA: low grade, when the mitosis count is $<5$ per $50 \mathrm{CGA}$, and high grade, when the count is $>5$ mitosis per 50 CGA. Regarding the histological grade, our cases presented the following behavior: low grade 41 cases $(75.9 \%)$ and high grade 13 cases $(24.1 \%)$ (Table 3 ).

The prognostic factors to be considered in the GIST are several and include localization, and tumors that originate in the small intestine and rectum have a worse prognosis ${ }^{24}$. Peritoneal or hepatic metastases are of worse prognosis.

Small tumors, incidental in the serosa, have a favorable course ${ }^{27}$. Other factors are tumor size, number of mitoses per 50 CGA, spontaneous or iatrogenic rupture of the tumor, affected surgical margins, necrosis, nuclear atypia, muscle, or mucosal invasion ${ }^{28}$. Ki $67>10 \%$ is associated with poor prognosis ${ }^{31}$. In the Mexican population, Martínez et al. ${ }^{29}$ found that the expression of p53 is greater in lesions of the intestine than in the stomach. Ki $67>10 \%$ is associated with poor prognosis ${ }^{30}$.

The treatment of choice is complete surgical resection; lymphadenectomy is not necessary since lymphatic dissemination is unlikely ${ }^{31}$. Lymphadenectomy was performed in 4 of our cases, and one of them identified metastases in 1 lymph node.

GIST is resistant to radio- and chemo-therapy and has recurrence or metastasis in $20 \%-50 \%$ of patients with resectable tumors; nevertheless, imatinib, in the postoperative period, has managed to improve recurrence-free survival. With imatinib, the best results are given when there is a mutation of exon 11 and greater resistance with mutations of exon 9 and the PDGFRa gene. When there is resistance, second-generation chemotherapy drugs such as sunitinib or regorafenib can be used ${ }^{32}$.

The application of micro-RNA (myRNA) in the treatment of GIST is under the study, and they are agents that can provoke an immune response ${ }^{17}$. The miRNA, which is small single-stranded RNA encoding 19-22 nucleotides, has the ability to regulate gene expression by translational inhibition or degradation of messenger RNA ${ }^{33}$.

Early diagnosis and radical resection of the primary lesion are the most appropriate treatment for healing.

In our cases, the main treatment used was surgical resection, and we do not have data on the subsequent evolution of patients.

\section{Ethical disclosures}

Protection of human and animal subjects. The authors declare that no experiments were performed on humans or animals for this study.

Confidentiality of data. The authors declare that they have followed the protocols of their work center on the publication of patient data.

Right to privacy and informed consent. The authors declare that no patient data appear in this article.

\section{References}

1. Herrera G. Historical Perspective: a Jurney Through Evolution of Classification Schemes, in US-CAP Companion Meeting Syllabus; 2003. p. 1-6.

2. Mazur MT, Clark HB. Gastric stromal tumors. Reappraisal of histogenesis. Am J Surg Pathol. 1983;7:507-19.

3. Herrera GA, Pinto de Moraes H, Grizzle WE, Han SG. Malignant small bowel neoplasm of enteric plexus derivation (plexosarcoma). Light and electron microscopic study confirming the origin of the neoplasm. Dig Dis Sci. 1984;29:275-84.

4. Barker PE, Rudolfe FH. Human c-kit oncogen of human chromosome 4. Am J Genet. 1985;37:A1431.

5. d'Auriol L, Mattei MG, Andre C, Galibert F. Localization of the human c-kit protooncogene on the q11-q12 region of chromosome 4 . Hum Genet. 1988;78:374-6. 
6. Kindblom LG, Remotti HE, Aldenborg F, Meis-Kindblom JM. Gastrointestinal pacemaker cell tumor (GIPACT): gastrointestinal stromal tumors show phenotypic characteristics of the interstitial cells of cajal. Am J Pathol. 1998;152:1259-69.

7. Min KW, Sook Seo I. Intestitial cells of cajal in the human small intestine: immunochemical and ultrastructural study. Ultrastruct Pathol. 2003;27 67-78.

8. Maeda H, Yamagata A, Nishikawa S, et al. Requirement of c-kit for development of intestinal pacemaker system. Development. 1992;116: 369-75.

9. Wang L, Vargas $\mathrm{H}$, French SW. Cellular origin of gastrointestinal stromal tumors: a study of 27 cases. Arch Pathol Lab Med. 2000;124:1471-5.

10. Kitamura Y, Hirotab S, Nishida T. Gastrointestinal stromaltumors (GIST): a model for molecular based diagnosis and treatment of solid tumors. Cancer Sci. 2003:94:315-20.

11. Lasota J, Jasinski M, Sarlomo-Rikala M, Miettinen M. Mutations in exon 11 of c-kit occur preferentially in malignant versus benign gastrointestina stromal tumors and do not occur in leiomyomas or leiomyosarcomas. Am J Pathol. 1999;154:53-60.

12. Heinrich MC, Corless CL, Duensing A, et al. PDGFRA activating mutations in gastrointestinal stromal tumors. Science. 2003;299:708-10.

13. Joensuu H, Roberts PJ, Sarlomo-Rikala M, et al. Effect of the tyrosine kinase inhibitor STI571 in a patient with a metastatic gastrointestinal stromal tumor. N Engl J Med. 2001;344:1052-6.

14. Miettinen M, Lasota J. Gastrointestinal stromal tumors-definition, clinical, histological, immunohistochemical, and molecular genetic features and differential diagnosis. Virchows Arch. 2001;438:1-2.

15. Ueyama T, Guo KJ, Hashimoto H, Daimaru Y, Enjoji M. A clinicopathologic and immunohistochemical study of gastrointestinal stromal tumors. Cancer. 1992;69:947-55.

16. Medina FH, Aguilar JJ, Medina ZJ. Tumores del estroma gastrointestinal Analisis de factores pronósticos en un grupo de pacientes mexicanos. Gac Med Mex. 2009;146:91-6.

17. Miettinen M, Lasota J. Gastrointestinal stromal tumors: review on morphology, molecular pathology, prognosis, and differential diagnosis. Arch Pathol Lab Med. 2006;130:1466-78.

18. González CR, Ramos AR, Vallejo BA. Tumores del estroma gastrointestinal: breve actualización y consenso de la SEAP-SEOM sobre diagnostico patológico y molecular. Rev Esp Patol. 2017:50:89-99.

19. Bodega QI, Tejedor TP, Sáenz GM, et al. Tumores del estroma gastrointestinal (GIST): serie del hospital central de la defensa gómez ulloa. Sanid Mil. 2013;69:173-81
20. Duensing A, Joseph NE, Medeiros F, et al. Protein kinase $C$ theta (PKCtheta) expression and constitutive activation in gastrointestinal stromal tumors (GISTs). Cancer Res. 2004;64:5127-31.

21. Blay JY. New paradigms in gastrointestinal stromal tumour management. Ann Oncol. 2009;20 Suppl 1:i18-24.

22. Agaram NP, Wong GC, Guo T, et al. Novel V600E BRAF mutations in imatinib-naive and imatinib-resistant gastrointestinal stromal tumors. Genes Chromosomes Cancer. 2008;47:853-9.

23. Miettinen M, Fetsch JF, Sobin LH, Lasota J. Gastrointestinal stroma tumors in patients with neurofibromatosis 1: a clinicopathologic and molecular genetic study of 45 cases. Am J Surg Pathol. 2006;30:90-6.

24. Fletcher CD, Berman JJ, Corless $C$, et al. Diagnosis of gastrointestinal stromal tumors: a consensus approach. Hum Pathol. 2002;33:459-65.

25. Medrano GR, Meza BK, Rodríguez SJ, Ávila GG. Factores pronóstico de recurrencia y supervivencia en tumors del estroma gastrointestinal. Experiencia del hospital de oncología del centro médico nacional siglo XXI instituto mexicano del seguro social. Gac Mex Oncol. 2015;14:259-67.

26. International Union Against Cancer (UICC). In: Sobin LT, Wittekind $\mathrm{CH}$, editors. TNM Classification of Malignant Tumors. $7^{\text {th }}$ ed. New York: Wiley; 2010.

27. DeMatteo RP, Lewis JJ, Leung D, et al. Two hundred gastrointestinal stromal tumors: recurrence patterns and prognostic factors for survival. Ann Surg. 2000;231:51-8.

28. Newman PL, Wadden C, Fletcher CD. Gastrointestinal stromal tumours: correlation of immunophenotype with clinicopathological features. J Pathol. 1991;164:107-17.

29. Martínez CN, Baquera HJ, de León BB, Padilla-Rodríguez A, Ortiz HC. Expresión de p53 y Bcl2 como marcadores pronóstico y de localización anatómica en tumors del estroma gastrointestinal. Estudio clinicopatológico e inmunohistoquímico de 19 casos. Rev Gastroenterol Mex. 2006;71:269-78.

30. Liang YM, Li XH, Li WM, Lu YY. Prognostic significance of PTEN, ki-67 and CD44s expression patterns in gastrointestinal stromal tumors. World J Gastroenterol. 2012;18:1664-71.

31. Koelz M, Lense J, Wrba F, et al. Down-regulation of miR-221 and miR222 correlates with pronounced kit expression in gastrointestinal stromal tumors. Int J Oncol. 2011;38:503-11.

32. Duensing S, Duensing A. Targeted therapies of gastrointestinal stromal tumors (GIST)-the next frontiers. Biochem Pharmacol. 2010;80:575-83.

33. Haller $F$, von Heydebreck A, Zhang JD, et al. Localization-and mutation-dependent microRNA (miRNA) expression signatures in gastrointestinal stromal tumours (GISTs), with a cluster of co-expressed miRNAs located at 14q32.31. J Pathol. 2010;220:71-86. 